\title{
Supplementation with Probiotics in the First 6 Months of Life Did Not Protect against Eczema and Allergy in At-Risk Asian Infants: A 5-Year Follow-Up
}

\author{
Evelyn X.L. Loo ${ }^{a}$ Genevieve V. Llanora $^{b}$ Qingshu Lu ${ }^{c, d}$ Marion M. Aw ${ }^{a, b}$ \\ Bee Wah Lee ${ }^{a, b}$ Lynette P. Shek ${ }^{a, b}$ \\ a Department of Paediatrics, Yong Loo Lin School of Medicine, National University of Singapore, 'b University Children's \\ Medical Institute, National University Hospital, ' Department of Biostatistics, Singapore Clinical Research Institute, and \\ ${ }^{d}$ Center for Quantitative Medicine, Office of Clinical Sciences, Duke-NUS Graduate Medical School, Singapore
}

\section{Key Words}

Allergy · Probiotics · Eczema

\begin{abstract}
Background: Healthy gut microflora is essential for oral tolerance and immunity. A promising approach to preventing allergic diseases in genetically at-risk infants is to introduce administration of probiotics early in life when their immune system is still relatively immature. Objective: In this followup study, we aim to determine if early-life supplementation with strains of probiotics has any long-term effect on allergic outcomes. Methods: We analyzed the charts and electronic databases of the PROMPT (Probiotics in Milk for the Prevention of Atopy Trial) study cohort. This cohort consisted of 253 infants at risk for allergy who were administered cow's milk supplemented with or without probiotics from the first day of life to the age of 6 months. The cohort was then followed up until the children were 5 years old and clinical outcomes were assessed. Results: Of the 253 children recruited into the study, 220 (87\%) completed the follow-up. At the age of 5 years, there were no significant differences between the groups in the proportion of children who had developed any asthma, allergic rhinitis, eczema, food allergy and sensitiza-
\end{abstract}

tion to inhalant allergens. Similar growth rates were observed in both groups. Conclusions: The supplementation of probiotics in early childhood did not play a role in the prevention of allergic diseases. Clinical/Key Message: Early-life supplementation with probiotics did not change allergic outcomes at 5 years of age.

(c) 2013 S. Karger AG, Basel

\section{Introduction}

We previously reported that feeding with cow's-milk formula supplemented with probiotics [Bifidobacterium longum (BL999) and Lactobacillus rhamnosus (LPR)] in the first 6 months of life in a cohort of Asian infants at risk for allergic disease did not prevent eczema or allergen sensitization in the first year of life [1]. Here, we report on the long-term effects on allergic outcomes at the age of 5 years.

Briefly, the subjects were randomized to receive a commercially available cow's-milk formula supplemented with or without probiotics from birth to 6 months of age. At follow-up visits from 1 month to 5 years of age, subjects were assessed for allergic outcomes. Diagnoses of

\begin{tabular}{ll}
\hline KARGER & $\begin{array}{l}\text { @ 2013 S. Karger AG, Basel } \\
1018-2438 / 14 / 1631-0025 \$ 39.50 / 0 \quad \text { Karger }\end{array}$ \\
E-Mail karger@karger.com & Thisis an Open Access article licensed under the terms of the \\
www.karger.com/iaa & $\begin{array}{l}\text { Creative Commons Attribution-NonCommercial 3.0 Un- } \\
\text { ported license (CC BY-NC) (www.karger.com/OA-license), } \\
\text { applicable to the online version of the article only. Distribu- } \\
\text { tion permitted for non-commercial purposes only. }\end{array}$
\end{tabular}

Correspondence to: Dr. Lynette P. Shek

Department of Paediatrics, Yong Loo Lin School of Medicine

National University of Singapore, NUHS Tower Block, Level 12

1E Kent Ridge Road, Singapore 119228 (Singapore)

E-Mail lynette_shek@nuhs.edu.sg 
Table 1. Comparison of incidence of atopic diseases by year up to the age of 5 years

\begin{tabular}{|c|c|c|c|c|}
\hline Clinical characteristics, n (\%) & $\begin{array}{l}\text { Probiotic } \\
(\mathrm{n}=124)\end{array}$ & $\begin{array}{l}\text { Placebo } \\
(\mathrm{n}=121)\end{array}$ & RR (95\% CI) & $\mathrm{p}$ value \\
\hline Ever had eczema & $(\mathrm{n}=124)$ & $(\mathrm{n}=121)$ & & \\
\hline By year 1 & $26(21.0)$ & $30(24.8)$ & $0.8(0.5-1.3)$ & 0.543 \\
\hline By year 2 & $27(21.8)$ & $32(26.4)$ & $0.8(0.5-1.3)$ & 0.456 \\
\hline By year 3 & $30(24.2)$ & $32(26.4)$ & $0.9(0.6-1.4)$ & 0.769 \\
\hline By year 4 & $30(24.2)$ & $35(28.9)$ & $0.8(0.6-1.3)$ & 0.470 \\
\hline By year 5 & $31(25.0)$ & $38(31.4)$ & $0.8(0.5-1.2)$ & 0.320 \\
\hline Ever had asthma & $(\mathrm{n}=124)$ & $(\mathrm{n}=121)$ & & \\
\hline By year 1 & $4(3.2)$ & $4(3.3)$ & $1.0(0.2-3.8)$ & 1.000 \\
\hline By year 2 & $11(8.9)$ & $11(9.1)$ & $1.0(0.4-2.2)$ & 1.000 \\
\hline By year 3 & $15(12.1)$ & $13(10.7)$ & $1.1(0.6-2.3)$ & 0.842 \\
\hline By year 4 & $20(16.1)$ & $17(14.0)$ & $1.1(0.6-2.1)$ & 0.722 \\
\hline By year 5 & $26(21.0)$ & $25(20.7)$ & $1.0(0.6-1.7)$ & 1.000 \\
\hline Ever had allergic rhinitis & $(\mathrm{n}=124)$ & $(\mathrm{n}=121)$ & & \\
\hline By year 1 & $1(0.8)$ & $1(0.8)$ & $1.0(0.1-15.4)$ & 1.000 \\
\hline By year 2 & $2(1.6)$ & $3(2.5)$ & $0.7(0.1-3.8)$ & 0.681 \\
\hline By year 3 & $5(4.0)$ & $4(3.3)$ & $1.2(0.3-4.4)$ & 1.000 \\
\hline By year 4 & $9(7.3)$ & $8(6.6)$ & $1.1(0.4-2.8)$ & 1.000 \\
\hline By year 5 & $16(12.9)$ & $23(19.0)$ & $0.7(0.4-1.2)$ & 0.223 \\
\hline Ever had food allergy since year 3 & $(\mathrm{n}=117)$ & $(\mathrm{n}=109)$ & & \\
\hline By year 3 & $1(0.9)$ & 0 & NA & 1.000 \\
\hline By year 4 & $1(0.9)$ & 0 & NA & 1.000 \\
\hline By year 5 & $1(0.9)$ & $1(0.9)$ & $1.1(0.1-17.0)$ & 1.000 \\
\hline \multicolumn{5}{|l|}{ Sensitization to inhalant allergens } \\
\hline At year 2 test & $(\mathrm{n}=118)$ & $(\mathrm{n}=111)$ & & \\
\hline Any sensitization & $20(16.9)$ & $19(17.1)$ & $1.0(0.6-1.8)$ & 1.000 \\
\hline Der $\mathrm{p}$ & $18(15.3)$ & $19(17.1)$ & $0.9(0.5-1.6)$ & 0.723 \\
\hline Blot & $5(4.2)$ & $6(5.4)$ & $0.8(0.2-2.5)$ & 0.763 \\
\hline Der f (not done) & NA & NA & NA & NA \\
\hline At year 5 test & $(\mathrm{n}=112)$ & $(\mathrm{n}=108)$ & & \\
\hline Any sensitization & $55(49.1)$ & $57(52.8)$ & $0.9(0.7-1.2)$ & 0.593 \\
\hline Der $\mathrm{p}$ & $46(41.1)$ & $51(47.2)$ & $0.9(0.6-1.2)$ & 0.415 \\
\hline Blot $t$ & $37(33.0)$ & $41(38.0)$ & $0.9(0.6-1.2)$ & 0.483 \\
\hline Der $\mathrm{f}$ & $44(39.3)$ & $47(43.5)$ & $0.9(0.7-1.2)$ & 0.584 \\
\hline
\end{tabular}

asthma, allergic rhinitis and eczema were made by pediatricians in the research team, and were based on a detailed history and clinical examination at yearly visits; food allergy was diagnosed by a history of convincing symptoms of food allergy and the presence of IgE allergen sensitization. Questionnaires were also administered at each visit to record potential sources of environmental exposure to allergens such as day-care, number of siblings, use of antibiotics, tobacco smoke and pets.

Of the 253 subjects who were recruited into the study, 245 (97\%) (124 receiving probiotics and 121 receiving placebo) completed at least 1 follow-up assessment, 231 (91\%) completed follow-up until the age of 2 years and $220(87 \%)$ until the age of 5 years. Compared to published studies, this is the largest cohort to have completed a follow-up to the age of 5 years. There were no significant differences in the baseline demographics and family history of allergic disease between the subjects who completed the follow-up and those who were lost to followup. For those who completed the 5-year follow-up, the probiotic and placebo groups did not differ significantly with regard to environmental factors. The proportion of subjects who had had any eczema since birth was similar in the probiotic and placebo groups (see table 1). Eczema severity was also similar, with a mean SCORAD (Scoring Atopic Dermatitis) score of 16.9 in the probiotic group and 15.3 in the placebo group $(\mathrm{p}=0.295)$. There were also no significant differences between the probiotic group 
and the placebo group in the proportion of subjects who had developed asthma (defined by 3 episodes of wheeze) or allergic rhinitis (see table 1). The proportion of subjects who had experienced any food allergy $(\mathrm{p}=1.000)$ as well as those sensitized to dust-mite allergens (Dermatophagoides pteronyssinus, Blomia tropicalis or D. farinae, $\mathrm{p}=$ 0.593 ) was also similar in the 2 groups. The growth rates as well as the rate of weight $(\mathrm{p}=0.660)$ and height $(\mathrm{p}=$ $0.996)$ gain were similar in the 2 groups.

It was noted that a large number of subjects $(208 / 226$ or $92 \%$ ) continued to consume probiotics of their own accord in the form of milk formula/food/supplements with probiotics at a frequency of at least once a week for at least 1 year from the age of 2 years. Incidentally, this practice was statistically associated with a reduced incidence of asthma and allergic rhinitis at the age of 5 years. Calculations of relative risk (RR) were made with adjustment for a subject's treatment group, i.e. probiotics or placebo. A diagnosis of asthma was made in 36 of 208 (17.3\%) subjects who had a weekly consumption of probiotics compared with 8 of 18 (44.4\%) who did not receive probiotics [adjusted RR 0.4 and 95\% confidence interval (CI) $0.2-0.7$ ]. Allergic rhinitis was diagnosed in 32 of 208 (15.4\%) with a regular consumption of probiotics and in 7 of 18 (38.9\%) subjects not receiving probiotics (adjusted RR 0.4 and 95\% CI 0.2-0.8). The incidence of asthma was found to be associated with duration of feeding with probiotics $(\mathrm{p}=0.002)$, but this was not observed for allergic rhinitis, eczema and allergen sensitization (data not shown). However, the possibility that these observations may in part have been confounded by reverse causality cannot be excluded. Those with symptomatic allergic rhinitis and asthma may have been less proactive in their consumption of probiotics. In addition, there was no reduction noted in the rate of eczema (RR 0.8 and 95\% CI $0.3-1.9, \mathrm{p}=0.543)$ or the sensitization to dust-mite allergens $(\mathrm{p}=0.154)$ with regular consumption of probiotics.

Healthy gut microflora is essential for oral tolerance and immunity. A promising approach to preventing allergic diseases in genetically at-risk infants is to introduce probiotics to them early in life when their immune system is still relatively immature [2]. However, whether or not probiotics indeed have a beneficial effect in the prevention of allergic diseases remains controversial. Some studies have shown the prevention of eczema $[2,3]$ while others do not find a reduction in allergic outcomes [4]. In addition, very few studies have looked at the long-term effects of probiotics on allergic diseases [5]. It is critical to report the long-term effects of early-life supplementation with probiotics, as respiratory allergies such as asthma, allergic rhinitis and sensitization to inhalant allergens often manifest later in life.

In our cohort, early supplementation in the first 6 months of life with probiotics did not change allergic outcomes at 5 years of age. Other studies using different bacterial strains have also demonstrated no effect; for example, early-life supplementation with Lactobacillus acidophilus was not found to exhibit long-term protective effects on allergic outcomes [5]. In contrast, the study by Kalliomaki et al. [6] showed a significantly decreased cumulative risk for the development of eczema with the use of the L. rhamnosus GG strain in a group of children in their first 7 years compared to a group receiving a placebo. The protective effect of $L$. rhamnosus in decreasing the cumulative prevalence of eczema was also reported in another study [3]. A possible reason for the protective effects observed by some groups could be the inclusion of prenatal supplementation as well as the dose of probiotics administered. Protective effects could also be attributed to specific bacterial strains [3]; the 2 bacterial strains we used in our study may have had a possible antagonistic effect [7]. We also did not observe any difference in growth rate with the use of probiotics; this is in line with a pooled analysis of previous trials which showed no significant differences in birth weight, length and BMI between infants who received Bifidobacterium lactis-supplemented infant formula and those that did not [8]. Interestingly, our study suggests that later and long-term probiotic supplementation could reduce the risk of allergic diseases. Another study recently reported that infants who received probiotic supplementation between 2 and 16 days after birth until 2 years of age had a significantly lower cumulative prevalence of eczema by the age of 4 years [9].

In conclusion, early-life supplementation with probiotics did not change allergic outcomes in children at the age of 5 years.

\section{Acknowledgments}

We acknowledge Nestlé for providing milk formula with and without probiotics as well as the assistance of the PROMPT (Probiotic in Milk for the Prevention of Atopy Trial) team. The voluntary participation of all subjects in this study is sincerely appreciated. This work was funded by the National Medical Research Council, Singapore (NMRC/0890/2004 and NMRC/CSA/ 022/2010). 


\section{References}

1 Soh SE, Aw M, Gerez I, Chong YS, Rauff M, $\mathrm{Ng}$ YP, et al: Probiotic supplementation in the first 6 months of life in at-risk Asian infants - effects on eczema and atopic sensitization at the age of 1 year. Clin Exp Allergy 2009; 39:571-578.

-2 Kalliomaki M, Salminen S, Arvilommi H, Kero P, Koskinen P, Isolauri E: Probiotics in primary prevention of atopic disease: a randomised placebo-controlled trial. Lancet 2001;357:1076-1079.

3 Wickens K, Black PN, Stanley TV, Mitchell E, Fitzharris P, Tannock GW, et al: A differential effect of 2 probiotics in the prevention of eczema and atopy: a double-blind, randomized, placebo-controlled trial. J Allergy Clin Immunol 2008;122:788-794.
4 Prescott SL, Wiltschut J, Taylor A, Westcott L, Jung W, Currie H, et al: Early markers of allergic disease in a primary prevention study using probiotics: 2.5-year follow-up phase. Allergy 2008;63:1481-1490.

5 Jensen MP, Meldrum S, Taylor AL, Dunstan JA, Prescott SL: Early probiotic supplementation for allergy prevention: long-term outcomes. J Allergy Clin Immunol 2012;130: 1209-1211.e5.

6 Kalliomaki M, Salminen S, Poussa T, Isolauri E: Probiotics during the first 7 years of life: a cumulative risk reduction of eczema in a randomized, placebo-controlled trial. J Allergy Clin Immunol 2007;119:1019-1021.
Pohjavuori E, Viljanen M, Korpela R, Kuitunen M, Tiittanen M, Vaarala O, et al: Lactobacillus GG effect in increasing IFN-gamma production in infants with cow's milk allergy. J Allergy Clin Immunol 2004;114:131-136.

8 Steenhout PG, Rochat F, Hager C: The effect of Bifidobacterium lactis on the growth of infants: a pooled analysis of randomized controlled studies. Ann Nutr Metabol 2009;55: 334-340.

9 Wickens K, Black P, Stanley TV, Mitchell E, Barthow C, Fitzharris $\mathrm{P}$, et al: A protective effect of Lactobacillus rhamnosus HN001 against eczema in the first 2 years of life persists to age 4 years. Clin Exp Allergy 2012;42: 1071-1079. 